\title{
The linguistic description of minimal social scenarios affects the extent of causal inference making th
}

\author{
Asifa Majid ${ }^{\mathrm{a}, *}$, Anthony J. Sanford ${ }^{\mathrm{b}}$, Martin J. Pickering ${ }^{\mathrm{c}}$ \\ a Max Planck Institute for Psycholinguistics, Nijmegen, The Netherlands \\ ${ }^{\mathrm{b}}$ University of Glasgow, Scotland, UK \\ ${ }^{\mathrm{c}}$ University of Edinburgh, Scotland, UK \\ Received 24 February 2006; revised 4 October 2006 \\ Available online 18 December 2006 \\ Communicated by John Skowronski
}

\begin{abstract}
There is little consensus regarding the circumstances in which people spontaneously generate causal inferences, and in particular whether they generate inferences about the causal antecedents or the causal consequences of events. We tested whether people systematically infer causal antecedents or causal consequences to minimal social scenarios by using a continuation methodology. People overwhelmingly produced causal antecedent continuations for descriptions of interpersonal events (John hugged Mary), but causal consequence continuations to descriptions of transfer events (John gave a book to Mary). This demonstrates that there is no global cognitive style, but rather inference generation is crucially tied to the input. Further studies examined the role of event unusualness, number of participators, and verb-type on the likelihood of producing a causal antecedent or causal consequence inference. We conclude that inferences are critically guided by the specific verb used.
\end{abstract}

(C) 2006 Elsevier Inc. All rights reserved.

Keywords: Social scenario; Event; Scenario; Verb; Inference; Cause; Causal antecedent; Causal consequence; Language

Causality is central to much of our construal of the social world, and it is a basic assumption of various theories of causal attribution that people seek explanations of social acts (e.g., Heider, 1958; Hewstone, 1989; Hilton \& Slugoski, 1986; Kelley, 1967). In social psychology, much of the literature on attribution shows that causal inferences are frequently made under diverse circumstances, a finding that presupposes that causal questions are being asked under diverse circumstances. Similarly, in the adult language comprehension literature, it has been suggested that events not given explicit explanations in discourse lead to people seeking an explanation, possibly by asking a causal

\footnotetext{
We thank Sandie Cleland, Jamie Pearson and Mitch Wells for assistance with running experiments and coding, and Kate Cavanagh, John Skowronski and three anonymous reviewers for their insightful comments on earlier versions of this paper.

* Corresponding author.

E-mail address: Asifa.Majid@mpi.nl (A. Majid).
}

question (Turnbull, 1986). All of this evidence is consistent with the claim that people ask causal questions during a wide range of information processing activities. In the present paper, we investigate whether minimal social scenarios, such as that described by John hugs Mary, lead people to focus on the causes of those events. We examine if people have a general preference for making causal inferences, and if so whether they make backward looking causal inferences to find an antecedent for the event, or forward looking causal inferences to find a possible consequence.

\section{Do people go beyond the information given?}

In both the social psychology and psycholinguistic literatures, there has been considerable interest in the patterns of causality triggered by various types of interpersonal verbs (see Rudolph \& Försterling, 1997, for a review). In these studies, participants are usually given an invitation to complete a simple sentence fragment ending with a causal 
connective such as John fascinated Mary because... In this case, their continuations typically continue with he, referring to John, because they likely assume that John has done something that caused him to fascinate Mary. In contrast, a fragment such as John praised Mary because... typically leads participants to continue with a reference to Mary, because they likely assume that Mary has done something praiseworthy. A considerable literature has catalogued this implicit causality bias (e.g., Au, 1986; Brown \& Fish, 1983; Corrigan, 1988, 1992; Fiedler \& Semin, 1988; Garvey \& Caramazza, 1974). Such studies assume that interpersonal verbs invite spontaneous causal attribution. However, the usual method of eliciting continuations has been to ask an explicit causal question, or to ask participants to complete a sentence fragment ending with "because." Such techniques do not answer the question of whether there is any spontaneous tendency to make causal attributions.

According to one viewpoint, causal questions are not generated for all events. The assumption being that inferences are effortful and the cognitive system limited, thereby making it implausible that causal inferences are generated ubiquitously. A representative statement capturing this viewpoint comes from Weiner (1985) who surmized that not all events will give rise to causal attribution since the time and effort to find a cause "may place cognitive strain on an organism" (Weiner, 1985, p. 82). This is not to say causal inferences are never made. If there is an explicit causal question (as in the implicit causality literature) then causal activity will ensue. We refer to this as the motivated tactician view (Fiske \& Taylor, 1991; Wyer \& Srull, 1989); causal inferences are made, but only when there is an explicit goal.

\section{Evidence for a preference for causal antecedents}

Although making inferences may be cognitively expensive, certain types of inferences play an essential role in our thinking. Schank (1986) has argued that the fundamental property of the cognitive system is its ability to explain its own, and others' actions. Attribution theories emphasize that causal attributions underlie our behavior, cognition, and emotion, and argue they are important for understanding since being able to locate the causal antecedents of an event helps predict what will happen in the future (e.g., C. A. Anderson, 1991; Heider, 1958; Hewstone, 1989; Kelley, 1967). According to this perspective, causal inferences constitute a core part of everyday thinking.

There is considerable evidence that people make spontaneous causal antecedent attributions, without an explicit causal question. Analyses of newspaper articles, for example, have shown a wealth of causal explanations for a diverse set of events, including sports events, political elections, and interpersonal events (as depicted in advice columns) (Försterling \& Groeneveld, 1983; Lau, 1984; Lau \& Russell, 1980; Shoenenman \& Rubanowitz, 1983 as reported in Weiner, 1985). Think-aloud protocols during reading show that explanations are more common than other kinds of inferences (Trabasso \& Magliano, 1996). When a causal link is not made explicit in a text, then there is an increase in reading time, during which readers make inferences in order to connect the new text fragment to the existing mental model in a causal fashion (e.g., Keenan, Baillet, \& Brown, 1984; Van den Broek, 1990; Zwaan \& Radvansky, 1998).

Certain conditions particularly promote causal inferences, including the occurrence of an unexpected or unusual event, non-attainment of a goal, the dependence of a perceiver on others for hedonically relevant outcomes, and the perceiver's own failure to perform a well-defined task satisfactorily (for overviews see Hastie, 1984; Kanazawa, 1992; Weiner, 1985).

\section{Evidence for a preference for causal consequents}

The majority of research has focused on inferences to the causal antecedent, but it is by no means obvious that there is a general preference for antecedents. A preference for causal consequences would be consistent with how much of narrative is structured-consecutive sentences tend to depict consecutive events (Chafe, 1979; Hopper, 1979). Stories by young children follow this default structure. A typical example is: "The baby cried. The mummy picked it up" (as told by a 3-year-old girl, analyzed in Sacks, 1972, see also Nelson, 1986). The second sentence in this story reports on the consequence (what happens next) of the main event depicted in the first sentence. There is also a processing advantage in adults for maintaining temporal order between events. Participants are faster at verifying a consequential relationship between two events (e.g., crimearrest) than an antecedent one (e.g., arrest-crime) (Fenker, Waldmann, \& Holyoak, 2005; see also Van der Meer, Beyer, Heinze, \& Badel, 2002; Zwaan, 1996).

Independently, Stevenson, Crawley, and Kleinman (1994) suggested that, all things being equal, people have a preference for information about the causal consequences of an event. So, rather than generating inferences about causal antecedents by default, they generate inferences about causal consequences. The evidence for the claim comes from a series of continuation studies, investigating referent preference in language production. More recently, Arnold (2001) presented participants with short passages ending in a sentence with a physical transfer event (e.g., John sent a telegram to Mary), which they had to continue with a new sentence. She found that there were more causal consequence than causal antecedent continuations.

\section{Evidence for massive inferential capacity}

It could be that both causal antecedent and causal consequence inferences are generated for social scenarios. Fiedler and Semin (1988) have argued that in real language use sentences are embedded in a set of antecedent and consequent sentences, and so when participants are presented with a sentence on its own they fill in these antecedent and 
consequent conditions. Similarly, Uleman and colleagues (e.g., Hassin, Bargh, \& Uleman, 2002; Uleman, 1999; Uleman, Newman, \& Moskowitz, 1996; Winter \& Uleman, 1984) have argued that people are constantly making a plethora of inferences: "People interpret the meaning of events spontaneously as well as tactically, and go beyond not only the information given, but also beyond the immediate demands of their proximal goals...People are flexible interpreters and have at their disposal a whole repertoire of cognitive procedures than they can deliberately deploy or "put on automatic"" (Uleman et al., 1996, pp. 269-270). This viewpoint has been dubbed the promiscuous inference generation account (Graesser, Millis, \& Zwaan, 1997).

A central component of this framework has been to show that people spontaneously (i.e., without intention, awareness, or effort) make inferences about many aspects of an event, including inferences about the protagonists such as their traits and emotional states (see Uleman, 1999). For example, when presented with a sentence such as Anna solved the mystery halfway through the book, participants infer the trait clever, even when there is no explicit instruction to do so (e.g., Winter \& Uleman, 1984). Similarly, people are better at learning the association between an actor and trait if they have previously been exposed to a description of the actor's trait-implying behavior. This suggests that the trait concept is activated during comprehension of the behavioral statement (Carlston \& Skowronski, 1994; Carlston, Skowronski, \& Sparks, 1995).

Crucially, Uleman and colleagues have argued that there is spontaneous generation of both causal antecedents and causal consequences (e.g., Hassin et al., 2002; Uleman, 1999). Hassin et al. had people read sentences such as After spending a day exploring beautiful sights in the crowded streets of New York, Jane discovered that her wallet was missing, and rate how interesting they were. This was followed by a 5 minute filler task, and then a surprise cuedrecall task for the sentences presented in the first part of the experiment. Cues were either implied causes (e.g., pickpocket) or words from the actual sentences (e.g., sights). Hassin et al. found that implied causes were better cues for retrieving the target sentences.

As evidence for causal consequence inferences being generated spontaneously, Hassin et al. (2002) cite McKoon and Ratcliff (1986), who showed that on reading The director and the cameraman were ready to shoot closeups when suddenly the actress fell from the 14th story, participants inferred dead, a causal consequence of the target sentence. ${ }^{1}$ They conclude "When taken together with the current find-

\footnotetext{
1 The evidence for spontaneous inferences to causal consequences is actually very weak. The majority of research shows that such inferences are either not made at all (e.g., Magliano, Baggett, Johnson, \& Graesser, 1993), or are only made when the eliciting information is foregrounded, the inference is strongly constrained by the story context, and it resolves a coherence break (Fincher-Kiefer, 1993; Keefe \& McDaniel, 1993; Murray, Klin, \& Myers, 1993), or when the task strategically encourages such inferences (Allbritton, 2004; Calvo, Castillo, \& Schmalhofer, 2006).
}

ings it seems, then, that the mind not only spontaneously attached a "cause tag"-it also attaches an "effect tag", hence, spontaneously covering the whole range of causal relations" (Hassin et al., 2002, p. 520). Thus, it could be that causal antecedent and causal consequence inferences are equally likely to be drawn.

\section{The present research}

In this paper, we investigate whether minimal social scenarios trigger consistent patterns of inference. By a minimal social scenario, we mean a single event with just two people, presented in isolation without background information (prior discourse). Examples are John hit Mary, John loved Mary, and John sent a telegram to Mary. We investigated inferences to these social scenarios using linguistic materials. Participants were presented with short sentences and asked to produce a written continuation. Asking people to produce continuations from vignettes reflects how people often think about social events, since much of social cognition is mediated through and with language (e.g., I. Anderson \& Beattie, 1996). This is not to imply that all social cognition is linguistically mediated, but clearly language plays a substantial and crucial role. This is reflected in the research paradigms employed in social psychology, where people are typically asked to respond to linguistic materials, and less often to real-life protagonists engaging in relevant behaviors.

Continuation data are the best way to examine whether there are consistent patterns of inference, since other measures (such as a probe task, for example) require the researcher to determine not only what type of inference people will make (causal antecedent or causal consequence), but also what the content of that inference will be. Differential reaction times could be due either to the type or the content of the inference. Given our focus is on the type of inferences people generate (regardless of content), open continuations are preferable. They also do not presuppose what particular inferences the participants will make.

What type of continuations might participants produce? Here, it is potentially important that researchers suggesting a preference for causal antecedents usually investigate "interpersonal" events, depicting an action or state between two people (e.g., Rudolph \& Försterling, 1997), whereas those arguing for a preference for causal consequences concentrate on events with little social significance, such as transfer of objects between people (e.g., Arnold, 2001; Stevenson et al., 1994). Thus we investigated whether differences among the types of verbs (and events they depict) may explain the differences in inferences generated, if there are any.

The causal antecedent account predicts that all minimal social scenarios will lead to inferences about possible antecedents of that event; whereas the causal consequent account predicts a general preference for consequences. The predictions from the motivated tactician account and the promiscuous inference generation account are less clear. 
Given that our experiments do not vary the task demands, the motivated tactician account does not predict differences in the inferences generated. However, this account is silent on whether causal antecedent or causal consequence inferences would be favored. The promiscuous inference generation account suggests that both causal antecedent and causal consequent inferences should be drawn for all events. Thus it provides no reason to expect a difference between the number of causal antecedent and causal consequence continuations. A final possibility is that different inferences are licensed by different verbs. To our knowledge there is no previous evidence suggesting that causal antecedent and causal consequence inferences may be determined by verb-type, but there is other evidence that suggests that this is a possibility. Most notably the work of Fiedler and Semin (Fiedler, Semin, \& Koppetsch, 1991; Semin \& Fiedler, 1988, 1989, 1992) has shown that different verbs license different inferences, such as how enduring an event is, how much information it reveals about the subject or about the situation, how easily the verb can be verified, and so on. Thus, it is plausible that causal inference generation may be crucially linked to the type of verb: Interpersonal verbs may trigger causal inferences, whereas physical transfer verbs may trigger consequential ones.

To distinguish these accounts, we began in Experiment 1 by asking participants to produce continuations to descriptions of events using interpersonal verbs, such as John hit Mary and John loved Mary, whereas in Experiment 2 we presented participants with a different kind of scenario, a literal transfer event such as John gave a book to Mary. We then examine what could be the basis for the kinds of inferences people draw under each of these conditions. Specifically, we examine the role of unusualness, the number of participators in the event, and the linguistic formulation of interpersonal events.

\section{Experiment 1: Inferences to interpersonal events}

Interpersonal events depict an action or state between at least two people. ${ }^{2}$ In English, the default way of expressing such relations is in a simple transitive sentence, such as John hit Mary or John liked Mary. There are two main classificatory systems used to describe interpersonal events: The Thematic Role Taxonomy (Brown \& Fish, 1983), which is derived from psycholinguistics; and the Linguistic Category Model (Semin \& Fiedler, 1988), which is derived from social cognition. Both systems are used in order to account for which participator ${ }^{3}$ will receive causal attribution. For example, people judge the cause of John feared

\footnotetext{
${ }^{2}$ In accord with social-psychological usage, event refers to both actions and states; note that in linguistics and psycholinguistics it is used to refer to actions exclusively.

${ }^{3}$ We use participator to refer to any entity participating in an event, be it a person or an object. The more common term used in the literature is participant, but we avoid it here since participant is also used to refer to people taking part in the experiment.
}

Mary to be Mary, but the cause of John frightened Mary to be John. Neither classificatory system predicts whether causal antecedent inferences (instead of causal consequential ones) would be generated in the absence of an explicit causal question. Nevertheless, we make use of the Thematic Role Taxonomy in this paper in order to facilitate discussion and make predictions about which classes of verbs would trigger which kinds of inferences. Although the Linguistic Category Model is superior in many ways, accounting for a wide array of social inferences from language not accounted for by the other model (Fiedler et al., 1991; Maass \& Arcuri, 1992; Semin \& Fiedler, 1988, 1989, 1992), we chose the Thematic Role Taxonomy because it has a classificatory scheme better suited for transfer verbs discussed in later experiments.

In this experiment we selected 100 verbs depicting both actions and states, and these are further divided into smaller classes. The classes are identified based on the properties of the participators: An Agent is the instigator of an action; a Patient is the recipient of the action; an Experiencer is someone having an experience; and finally a Stimulus is someone, or something, giving rise to an experience. Agent/Patient and Stimulus/Experiencer form exclusive pairs of participator roles. Agent-Patient verbs depict actions of various kinds (e.g., hug, telephone, praise), whereas Stimulus-Experiencer verbs depict states. There are two classes of state verbs: Stimulus-Experiencer verbs (e.g., frighten, fascinate) and Experiencer-Stimulus verbs (e.g., fear, respect). The difference between the two is whether the subject of the sentence is the one giving rise to the experience (Stimulus-Experiencer verbs) or having the experience (Experiencer-Stimulus verbs). In this experiment we test the prediction that these three classes of verbs will lead to a preference for causal antecedents.

\section{Method}

\section{Participants}

Forty-eight University of Glasgow undergraduates participated in this experiment. In all experiments, participants were native speakers of English, and no-one took part in more than one experiment reported in this paper.

\section{Materials and design}

A hundred verbs were randomly selected from a corpus consisting of interpersonal verbs previously used in the literature on causal attribution or taken from Levin (1993). There were 57 Agent-Patient verbs, 20 Stimulus-Experiencer verbs, and 23 Experiencer-Stimulus verbs, a distribution comparable to the actual frequency of such verbs in English (Rudolph \& Försterling, 1997). The verbs were randomly divided into two lists with the constraint that each list had roughly equal numbers of each sort of verb. Every verb was paired with two proper names, one stereotypically male and one stereotypically female, such as Ted loved Mary (see Appendix A). Each sentence was presented with a period and two blank lines. The ordering of the male and 
female names was counterbalanced across booklets. Four random presentation orders were used.

\section{Procedure}

Participants were tested either individually or in small groups. Each participant received a booklet and was asked to read each sentence and provide a continuation in the space provided. They were told there was no right or wrong answer.

\section{Coding procedure}

There were three main categories of response: causal antecedent, causal consequence, and simple elaboration. The categories reflect possible temporal focus points-to the antecedent (i.e., the preceding event), to the consequence (i.e., to the following event), or to the target event itself. All remaining continuations were coded into a single "other" category. Our primary interest is whether people spontaneously focus on the causal antecedent or consequence.

Causal antecedent. A continuation was coded as a causal antecedent if it began with because (or an abbreviation such as 'cause or 'coz). When it was not employed, the criterion of "necessity in the circumstances" was used (Mackie, 1980; see also Einhorn \& Hogarth, 1986; Trabasso \& Sperry, 1985; Trabasso \& Vandenbroek, 1985). Judges coded a continuation as a causal antecedent if under the circumstances the continuation had not happened then the event in the main clause would not have happened. Examples of antecedent continuations to John loved Mary were Because she was so sweet, Cause of her personality and She was irresistible.

Causal consequence. If the continuation began with so, or some equivalent term (e.g., and so) then it was coded as a causal consequence. If such a term was not used, we reversed the criterion for identifying causal antecedent relations. Following Trabasso and Sperry (1985, p. 598), it was assumed that "the consequence is dependent in some manner on the cause or that the cause determines the consequence." Hence, a continuation was defined as a causal consequence if under the circumstances the event in the main clause had not happened then the continuation would not have happened. Examples of causal consequence continuations to John loved Mary were And so he brought her flowers and He could not live without her. Continuations that reflected what happened next were also coded in this category, for example continuing John apologized to Mary with And then they went for pizza.

Simple elaboration. A simple elaboration provided information that modified the target event in some way. The coders were instructed to code simple elaborations "if the location or time the event happened or the manner in which the event was carried out was mentioned." An example of each type of continuation was also given to the coder: John apologized to Mary in the garden (location), John apologized to Mary in the morning (time), and John apologized to Mary loudly (manner). If the continuation introduced another participator (e.g., 's friend, as in John apologized to Mary's friend) then the continuation was also coded as a simple elaboration. Simple elaborations do not introduce a new event, but rather provide more information about the target event itself.

Two judges were given the coding criteria and then independently coded the 2400 continuations. Cohen's kappa statistic was $\kappa=.89, S E=.007, p<.0001$ (Cohen, 1960), almost perfect agreement according to Landis and Koch (1977). Data from one judge were chosen by random for all analyses for this experiment.

\section{Results}

Two analyses were conducted for each verb class, treating participants and items as random effects. Items analyses are typically used in experiments employing language stimuli in order to demonstrate that the findings generalize beyond the particular items used in the current experiment (Clark, 1973). The crucial question is whether causal antecedent or causal consequence continuations were preferred for the three classes of verbs. To test this, we calculated for each participant how many continuations were produced to the causal antecedent and how many to the consequent; for items we followed the same procedure, calculating for each item how many antecedent and consequent continuations were elicited.

In all analyses there were significantly more causal antecedent continuations than causal consequent ones: Agent-Patient verbs Wilcoxon-T: participants $z=5.73$, $p<.0001$; items $z=6.00, p<.0001$; Stimulus-Experiencer verbs Wilcoxon-T: participants $z=5.61, p<.0001$; items $z=3.89, p<.0001$ and Experiencer-Stimulus verbs Wilcoxon-T: participants $z=4.59, p<.0001$; items $z=3.83$, $p<.0001$. The percentage of continuations to each of the categories is shown in Table 1 (see also Fig. 1a). Causal antecedent continuations accounted for $75.9 \%$ of the data overall.

Table 1

Percentage of continuations for Experiment 1

\begin{tabular}{lcccc}
\hline Verb-type & \multicolumn{4}{c}{ Continuation type } \\
\cline { 2 - 5 } & $\begin{array}{c}\text { Causal } \\
\text { antecedent }\end{array}$ & $\begin{array}{c}\text { Causal } \\
\text { consequence }\end{array}$ & $\begin{array}{c}\text { Simple } \\
\text { elaboration }\end{array}$ & Other \\
\hline $\begin{array}{c}\text { Agent-Patient } \\
\text { (e.g., Barry hugged Joan) }\end{array}$ & 71.5 & 17.7 & 9.9 & 0.9 \\
$\begin{array}{c}\text { Stimulus-Experiencer } \\
\text { (e.g., Gail frightened }\end{array}$ & 86.0 & 10.6 & 2.3 & 1.1 \\
$\begin{array}{c}\text { Matthew) } \\
\text { Experiencer-Stimulus } \\
\text { (e.g., Florence feared }\end{array}$ & 70.3 & 16.7 & 12.1 & 0.9 \\
$\quad$ Sebastian) & & & & \\
\hline
\end{tabular}


A

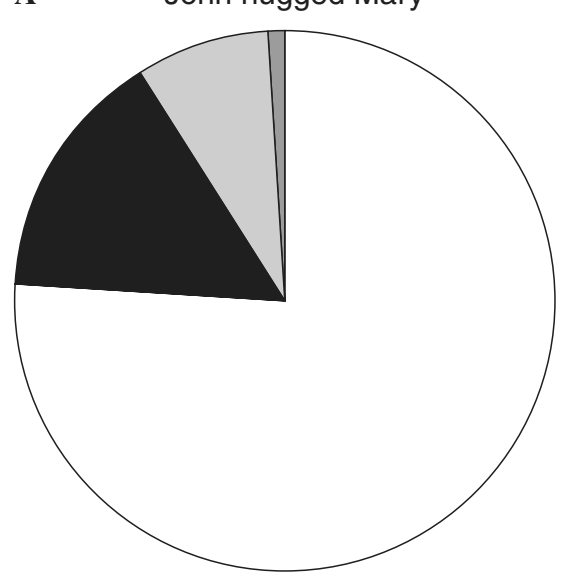

C

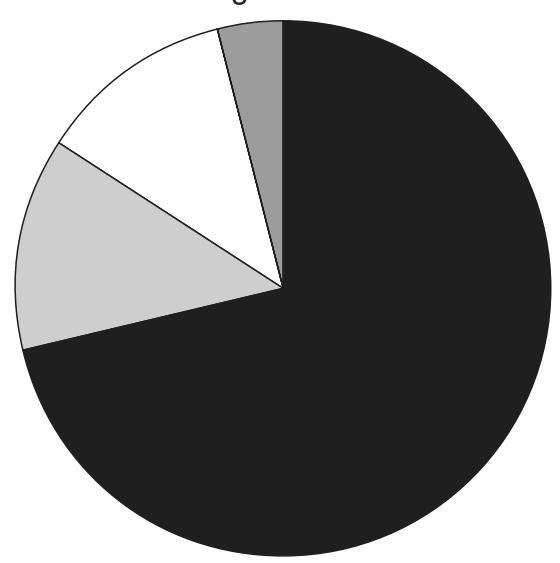

B John got a ticket from Mary

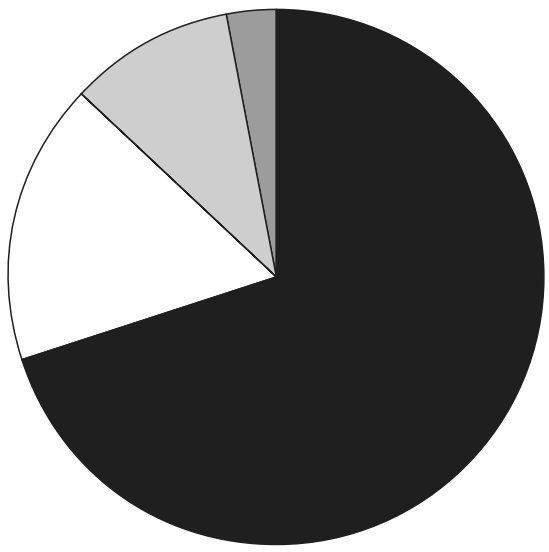

D John got a hug from Mary

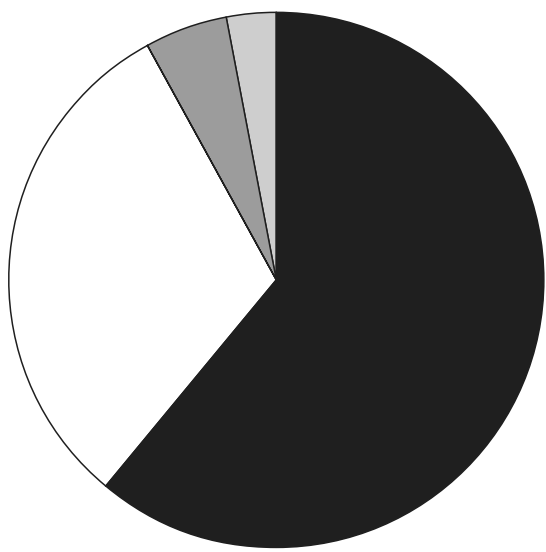

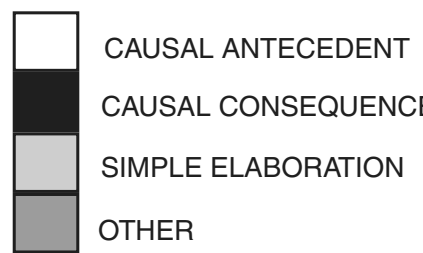

Fig. 1. Continuations to Experiment 1 (A), Experiment 2 (B), Experiment 4 (C), and Experiment 5 (D).

\section{Discussion}

Causal antecedent completions were overwhelmingly preferred to all other types of continuations. For all three verb types, participants focused on the event that brought about the target event. This is consistent with the hypotheses that interpersonal verbs in particular put an emphasis on causal antecedents, and that there is a general preference for antecedents.

Experiment 1 is inconsistent with the view that there is a general preference for causal consequences as suggested by Stevenson et al. (1994) and seems to be at odds with the empirical findings presented by Arnold (2001). We consider two possible explanations for this discrepancy. First, events depicting interpersonal events may simply lead to more causal antecedent continuations than other types of verb. Arnold exclusively used verbs depicting physical transfer events (e.g., John got a ball from Mary), where an object ( $a$ ball) is transferred from a Goal (John) to a Source (Mary). ${ }^{4}$ It could be that these verbs do not elicit causal antecedent inferences, but rather causal consequence ones.

Second, Arnold's (2001) materials were more complex than those in Experiment 1. Rather than use single sentences, she set her sentences in fuller passages. It could be that this prior context provided people with causal antecedent information, which meant that participants no longer focused on the antecedent as they had been provided with that information. If causal antecedent information was already provided, participants might then focus on a causal consequence relation (i.e., what happened next). In Experiment 2, we stripped away the contextual support from

\footnotetext{
${ }^{4}$ Like states, physical transfer events can vary in their syntactic structure, with the Goal either occurring as the sentence subject in Goal-Source verbs (e.g., get, catch, receive) or as the object in Source-Goal verbs (e.g., pass, tell, give).
} 
Arnold's sentences in order to establish whether, under conditions comparable to our Experiment 1, the focus on causal consequences still emerges in continuations.

\section{Experiment 2: Inferences to physical transfer events}

\section{Method}

\section{Participants}

Twenty-four further University of Glasgow undergraduates participated in this experiment. One of the participants did not complete the booklet and so was not included in the analyses.

\section{Materials and design}

The materials were taken from Arnold (2001). We used the target sentence exactly as it appeared in the Appendix of Arnold (Appendix B). Each item consisted of a physical transfer verb, introduced by either a Goal-Source verb (e.g., John got a ticket from Mary) or a Source-Goal verb (e.g., John passed the ball to Mary). Each verb was paired with a stereotypically male and a stereotypically female proper name. As in Experiment 1, the order of the names was counterbalanced across booklets. A total of 32 items were presented to each participant. We presented the items in six different random orders.

\section{Procedure}

This was the same as Experiment 1.

\section{Coding}

The responses were coded and analyzed as before. The measure of agreement between the two judges was almost perfect, $\kappa=.84, S E=.02, p<.0001$. Disagreements were resolved through discussion.

\section{Results}

We examined the number of causal antecedent and causal consequent continuations produced for the two types of verbs, using participant and item level analyses. Both Goal-Source and Source-Goal verbs gave rise to significantly more causal consequent continuations then antecedent ones: Goal-Source Wilcoxon-T: participants $z=3.64, p<.0001$; items $z=3.53, p<.0001$ and SourceGoal Wilcoxon-T: participants $z=4.03, p<.0001$; items $z=3.52, p<.0001$. Table 2 shows the percentage of continuations to each category (see also Fig. 1b). Overall $70.1 \%$ of continuations were to causal consequents.

\section{Discussion}

For physical transfer verbs expressed by both GoalSource and Source-Goal verbs, causal consequence completions were the most frequent. This is consistent with the findings of Arnold (2001), and our manipulation showed that the extra context provided by Arnold was not the reason for the difference between her observations and those found in our
Table 2

Percentage of continuations for Experiment 2

\begin{tabular}{lcccc}
\hline Verb-type & \multicolumn{4}{c}{ Continuation type } \\
\cline { 2 - 5 } & $\begin{array}{c}\text { Causal } \\
\text { antecedent }\end{array}$ & $\begin{array}{c}\text { Causal } \\
\text { consequence }\end{array}$ & $\begin{array}{c}\text { Simple } \\
\text { elaboration }\end{array}$ & Other \\
\hline $\begin{array}{c}\text { Goal-Source } \\
\text { (e.g., Jason passed } \\
\text { the ball to Holly) }\end{array}$ & 19.0 & 64.9 & 12.5 & 3.5 \\
$\begin{array}{c}\text { Source-Goal } \\
\text { (e.g., Gabrielle got a }\end{array}$ & 15.8 & 75.3 & 7.1 & 1.9 \\
ticket from Rafael) & & & & \\
\hline
\end{tabular}

Experiment 1. The preference for causal consequence continuations suggests that verbs denoting the transfer of physical objects puts a focus on what happens next, with or without prior discourse (as provided by Arnold).

One explanation for the lack of causal antecedent continuations in Experiment 2 could be that the materials depict events that are more commonplace than those depicted in Experiment 1. There is reason to think that unusual events trigger search for causal antecedents (Hastie, 1984; Kanazawa, 1992; Schank, 1986; Weiner, 1985). For instance, Hilton and Slugoski (1986) demonstrated that deviations from scripted events, for example Mary buys nothing on her visit to the supermarket, lead to causal attributions because they deny presuppositions about usual behavior in supermarkets. Similarly, where participator roles are unusual, as in The son praised the father, more causal attributions are elicited than when the roles are more usual, as in The father praised the son (Garvey \& Caramazza, 1974). It is possible that the interpersonal events in Experiment 1 (e.g., John hit Mary) may be more unusual than simple physical transfer events in Experiment 2 (e.g., John gave a book to Mary). We tested this possibility in Experiment 3 by asking participants to rate the events from Experiments 1 and 2 for unusualness.

\section{Experiment 3: Event unusualness as a predictor of causal antecedent continuations}

\section{Method}

\section{Participants}

Twenty-four University of Glasgow undergraduates participated in this experiment.

\section{Materials and design}

All verbs from Experiments 1 to 2 were included in the rating study: Fifty-seven Agent-Patient verbs, 20 StimulusExperiencer verbs, and 23 Experiencer-Stimulus verbs from Experiment 1; and 16 Goal-Source and 16 Source-Goal verbs from Experiment 2. The verbs were presented as before with stereotypically male and female names, and the order of the names was counterbalanced across booklets. Each item was followed by a $10 \mathrm{~cm}$ long rating scale with "extremely unusual" marked on one end, and "not at all unusual" at the other. Items were presented in four different random orders. 


\section{Procedure}

Participants received a booklet and were asked to read each sentence carefully and then mark on the scale beneath how unusual the event was. They were told all judgments were relative to one another, and that they should use the full range of the scale. Participants' responses were measured to the nearest millimeter, with 0 meaning that the event was judged to be extremely unusual and 100 that it was judged to be not at all unusual.

\section{Results and discussion}

In order to test whether the interpersonal events of Experiment 1 were more unusual than the physical transfer events of Experiment 2, we compared the unusualness ratings and found a large effect of event type $[t(130)=4.90$, $p<.0001, d=.86]$. Interpersonal events were rated as more unusual $(M=67.2)$ than physical transfer events $(M=83.5)$, as predicted.

To test more directly the relationship between unusualness of the event and causal antecedent continuations, we correlated the ratings from this study with the frequency of causal antecedent continuations from Experiments 1 and 2. There was a significant negative correlation $[r(130)=-.42$, $p<.0001]$ between unusualness ratings $(M=60.9)$ and causal continuations $(M=17.9)$. That is, the more unusual an event was rated to be, the more causal antecedent continuations it received. Thus unusualness appears to play a role in whether a causal question is asked, and accounts for around $18 \%$ of the variance. However, this relationship is stronger for interpersonal verbs than transfer verbs. Separate correlations by verb type show that there was a significant negative correlation $[r(98)=-.34, p<.0001]$ between unusualness ratings $(M=67.2)$ and causal antecedent continuations $(M=21.6)$ for interpersonal verbs, but no significant relationship $[r \quad(30)=-.11, \quad p=.29]$ between unusualness $(M=83.5)$ and causal continuations $(M=4.0)$ for transfer verbs. It is difficult to interpret this lack of correlation, since at $\alpha=.05$ and $N=32$ the power for detecting an effect for the transfer verbs is only .15 (Faul \& Erdfelder, 1992).

Overall, the more unusual an event was deemed to be, the more likely it was to elicit a causal antecedent continuation. A substantial portion of the variance was accounted for by unusualness, suggesting that people tend to focus on causal antecedents when events are unusual. Perceived unusualness is one factor that might explain why events based on interpersonal verbs tend to induce causal antecedent continuations. However, there are other differences between transfer verbs and interpersonal verbs. First, transfer verbs describe events involving three participators. For instance, John got a ticket from Mary has John, Mary, and a ticket. In contrast, the interpersonal verbs studied in Experiment 1 describe events involving only two participators. Perhaps number of participators changes the pattern of continuations. We examined this possibility in Experiment 4.

\section{Experiment 4: Inferences to physical transfer events with two participators}

\section{Method}

\section{Participants}

Twenty-four University of Edinburgh undergraduates participated.

\section{Materials and design}

The materials were the same as those in Experiment 2, but were missing the prepositional phrase (to or from plus the name). An example is Frank sold the couch (see Appendix B). Half the items had a stereotypically male name, the other half had a stereotypically female name. A total of 32 items were presented to each participant. Items were presented in six different random orders.

\section{Procedure}

The procedure was the same as in Experiment 1.

\section{Coding}

The measure of agreement between the two judges was almost perfect, $\kappa=.83, S E=.01, p<.0001$. Disagreements were resolved through discussion.

\section{Results}

The question of interest is whether there is a preference for causal antecedent or causal consequence continuations. If verbs with two participators trigger a search for a causal antecedent then we would expect more causal antecedent continuations. On the other hand, if the type of event is crucial, then we would expect more causal consequence continuations. For both Goal-Source and Source-Goal verbs, we conducted participant and item analyses to compare the number of continuations produced to causal antecedents and consequents.

It appears that number of participators is not crucial for the type of inference made. Causal consequence continuations were produced significantly more often than causal antecedent continuations for both Goal-Source verbs Wilcoxon-T: participants $z=4.30, p<.0001$; items $z=3.52$, $p<.0001$ and Source-Goal verbs Wilcoxon-T: participants $z=4.29, p<.0001$; items $z=3.52, p<.0001$. Overall $71.2 \%$ of continuations were to consequences. The proportion of continuations to each of the categories is shown in Table 3 (see Fig. 1c).

\section{Discussion}

We hypothesized that number of participators could be a crucial variable underlying the preference for causal antecedents displayed in Experiment 1 on the one hand, and the preference for causal consequences in Experiment 2 on the other hand. In this experiment, verbs from Experiment 2 were presented to participants with one participator omitted, 
Table 3

Percentage of continuations for Experiment 4

\begin{tabular}{lcccc}
\hline Verb-type & \multicolumn{3}{c}{ Continuation type } \\
\cline { 2 - 5 } & $\begin{array}{c}\text { Causal } \\
\text { antecedent }\end{array}$ & $\begin{array}{c}\text { Causal } \\
\text { consequence }\end{array}$ & $\begin{array}{c}\text { Simple } \\
\text { elaboration }\end{array}$ & Other \\
\hline $\begin{array}{l}\text { Goal-Source } \\
\text { (e.g., Jason passed } \\
\text { a ball) }\end{array}$ & 13.8 & 67.7 & 15.6 & 2.9 \\
$\begin{array}{l}\text { Source-Goal } \\
\text { (e.g., Gabrielle got } \\
\text { a ticket })\end{array}$ & 9.4 & 75.8 & 9.6 & 5.2 \\
\hline
\end{tabular}

so that only two participators were present. Nevertheless, participants produced more causal consequence continuations than any other kind of relation, and the results were almost identical to those of Experiment 2 where all three participators were present. It seems that number of participators is not a determinant of continuation type.

Another possibility is that continuations are determined by event type: Interpersonal events focus attention on causal antecedents, but transfer events focus attention on causal consequences. To investigate this possibility, we first note that Goal-Source type verbs, such as get, receive, pass, and toss, can be used to depict physical transfer (e.g., got a ticket, received a telegram, passed the ball, tossed the egg), but they can also be used metaphorically to depict an interpersonal scenario. For example, got a hug, received praise, passed the blame, and tossed a kiss do not describe a literal transfer. People understand these expressions as referring to interpersonal scenarios, akin to those expressed in Experiment 1. Hence in Experiment 5 we asked whether sentences such as John got a hug from Mary produce causal antecedent continuations, as do sentences such as John hugged Mary, or causal consequence continuations, as do sentences such as John got a ticket from Mary.

\section{Experiment 5: Inferences to metaphorical transfer events}

In Experiment 3 we saw that interpersonal events were deemed to be more unusual than physical transfer events. This unusualness may reflect something deep about the kinds of interactions that trigger causal antecedent inferences: Interpersonal events depict interactions that are more noteworthy; whereas transfer events seem mundane. However, we can take the verbs used to depict transfer events, and make them depict events that are interpersonal. The metaphorical expression sent conflicting signals, for instance, represents a state affairs between two people that is socially loaded. Do such expressions trigger causal antecedent inferences because of their interpersonal status, or causal consequence completions because of the use of the verb sent (as in sent a telegram)?

We took the verbs used in Experiment 2 and changed the direct object (the object of transfer) so that the new expression depicted an interpersonal event, akin to those presented in Experiment 1. Some of these expressions have no direct counterpart in Experiment 1 (e.g., there is no single verb which means sent conflicting signals), and others were a paraphrase of a simpler expression from Experiment 1 (John hugged Mary from Experiment 1 can be paraphrased as John got a hug from Mary).

If the interpersonal scenario is crucial to determining patterns of inferences, then John got a hug from Mary should lead to causal antecedent continuations, as did sentences like John hugged Mary. However, if the specific verb is critical then causal consequence continuations should predominate for John got a hug from Mary as they did for John got a ticket from Mary.

\section{Method}

\section{Participants}

Twenty-four University of Glasgow undergraduates participated.

\section{Materials and design}

The materials were adapted from Experiment 2. The direct object was changed so that the object of transfer was not a physical object, but an abstract object. This changed the event into a metaphorical expression depicting an interpersonal event (see Appendix C). Items were presented with male and female names. A total of 29 items were created with 14 Goal-Source verbs and 15 Source-Goal verbs. (It was not possible to substitute abstract objects for every transfer event used in Experiment 2.) We conducted an unusualness rating study of these events (as in Experiment 3) comparing the new expressions with the equivalent Goal-Source verbs from Experiment 2 (e.g., between Rafael got a ticket from Gabrielle and Rafael got a hug from Gabrielle). Numerically there were slightly higher ratings of unusualness for simple transfer events, such as got a ticket $(M=64.9)$, than there were for interpersonal transfer events, such as got a hug $(M=60.5)$, but this was not statistically significant $[t(56)=1.26, p=.22]$.

\section{Procedure}

The procedure was as in Experiment 1.

\section{Coding}

The measure of agreement between the two judges was substantial, $\kappa=.77, S E=.02, p<.0001$. Disagreements were resolved through discussion.

\section{Results and discussion}

If interpersonal events trigger causal antecedent attributions then there should be more causal antecedent continuations than causal consequence ones. On the other hand, if the specific verb is the crucial variable, then there should be more causal consequence continuations. For each verb class we conducted participant and item analyses comparing the number of continuations to both antecedents and consequences. There were significantly more causal consequence continuations produced than causal antecedent 
Table 4

Percentage of continuations for Experiment 5

\begin{tabular}{lcccc}
\hline Verb type & \multicolumn{4}{c}{ Continuation type } \\
\cline { 2 - 5 } & $\begin{array}{c}\text { Causal } \\
\text { antecedent }\end{array}$ & $\begin{array}{c}\text { Causal } \\
\text { consequence }\end{array}$ & $\begin{array}{c}\text { Simple } \\
\text { elaboration }\end{array}$ & Other \\
\hline $\begin{array}{c}\text { Goal-Source } \\
\text { (e.g., Jason passed } \\
\text { the blame to Holly) }\end{array}$ & 30.6 & 60.7 & 4.5 & 4.2 \\
$\begin{array}{c}\text { Source-Goal } \\
\text { (e.g., Gabrielle got } \\
\text { a hug from Rafael) }\end{array}$ & 31.9 & 61.9 & 1.1 & 5.0 \\
\hline
\end{tabular}

ones for Goal-Source verbs Wilcoxon-T: participants $z=3.01, p<.003$; items $z=2.38, p<.02$, and for SourceGoal verbs Wilcoxon-T: participants $z=2.41, p<.02$; items $z=2.70, p<.007$. Overall $61.3 \%$ of continuations were to causal consequences. The proportion of continuations to each of the categories is shown in Table 4 (see Fig. 1d).

Metaphorical transfer depicting an interpersonal event led to more causal consequence continuations than causal antecedent ones. This suggests that the type of verb is more important than the particular scenario depicted. In other words, the type of verb, rather than the type of scenario, appears to predict the type of continuation. However, does the type of scenario have any effect on continuations? Our question was whether changing the type of transfer, from a physical one to a metaphorical one depicting an interpersonal event, would increase the number of causal antecedent continuations. Although causal consequence completions were still strongly preferred for abstract transfer events, we can still examine whether there was a boost to the causal antecedent continuations by comparing the continuations in this experiment to those in Experiment 2. Thus, we can directly compare continuations to sentences such as Rafael got a ticket from Gabrielle and Rafael got a hug from Gabrielle. A between-participants and -items comparison showed that causal antecedent continuations in the current experiment increased significantly in comparison to antecedent continuations in Experiment 2 in both the participants analysis $t(92)=2.93, p<.004, d=.58$ and the items analysis $t(59)=3.93, p<.0001, d=.92 \quad$ (Experiment 2, $M=2.78$; Experiment 5, $M=4.54$ ). This suggests that there is an effect of the interpersonal scenario that bolsters causal antecedent continuations. Note that this effect is not due to unusualness as we controlled for this in our construction of these materials.

\section{General discussion}

In this paper, we present evidence that even in the absence of an explicit question, inferences generated by people are systematically related to the input. When faced with descriptions of simple, interpersonal and socially significant acts, such as John hugged Mary, people overwhelmingly make causal antecedent attributions. However, when presented with other acts, for example physical transfer events such as John gave a book to Mary, the preference for antecedents disappears, and instead there is a strong preference for causal consequences. These findings are inconsistent with the motivated tactician view (Fiske \& Taylor, 1991; Wyer \& Srull, 1989), which proposes that people only make inferences when there is some explicit goal to do so. In these experiments instructions were held constant, and yet people systematically favored causal antecedent inferences in one case and causal consequence inferences in the other.

These findings are also inconsistent with the view that the cognitive system has a ubiquitous preference for causal antecedents, as is supposed in much cognitive science (e.g., Schank, 1986), social cognition (e.g., Heider, 1958; Kelley, 1967), and text comprehension research (e.g., Graesser, Singer, \& Trabasso, 1994). We show that this is not a general preference, as has been presupposed, but instead the focus of attention is shaped by the particular linguistic utterance under consideration. Similarly, the findings are inconsistent with the view that there is a general preference for causal consequences, as is supposed in much psycholinguistic research (e.g., Arnold, 2001; Stevenson et al., 1994). Interpersonal verbs predominantly gave rise to causal antecedent continuations, not consequences as is predicted by this view.

Finally, our results suggest that not all inferences are equally likely to be generated, as suggested by the promiscuous inference generation account, or at least they are not equally likely to make it to consciousness. Hassin et al., (2002; Uleman, 1999) suggested that on reading an event the whole range of causal relations are spontaneously generated, including both the causal antecedent and the causal consequence. Our findings suggest that there is differential activation of causal antecedent and causal consequence inferences as a function of the verb. Our studies do not address the time course of this inferential activity - it could be that both types of inferences are equally available early on, but one wins out over time; or alternatively there could be a preference for causal antecedents or causal consequences immediately on encountering the verb. It remains to future research to distinguish these possibilities.

\section{What underlies the preferences for causal antecedents or causal consequences?}

Why are causal antecedent questions asked for some sorts of events, but causal consequence questions for others? (See Fig. 1.) We consider some possible explanations below. Potential explanations are unusualness, the number of participators, and the socialness of the scenario. We argue that none of these can account for the essential difference in continuations. Instead it seems that it is the verb itself that determines whether a causal antecedent or a causal consequence will be inferred. Two likely mechanisms are the morphology of the verb as reflected in trait-implicating derived adjectives, and the grammatical construction that the verb forms part of. 


\section{Unusualness}

Part of the answer seems to lie in properties of the events themselves, such as how unusual they are. It is well-established that unusual scenarios or unusual participators can lead to more inferences to the causal antecedent (Garvey \& Caramazza, 1974; Hastie, 1984; Hilton \& Slugoski, 1986; Kanazawa, 1992; Schank, 1986; Weiner, 1985). In Experiment 3 we showed that participants view scenarios such as John hugged Mary as more unusual than John gave a book to Mary. This suggests that expectancies about unusualness can trigger inferences to the causal antecedent. But unusualness is only one component in accounting for continuation types. More importantly Experiment 3 does not rule out a different possibility, namely that the unusualness ratings are a result of whether an antecedent inference is likely to be generated by the scenario presented, rather than the other way round.

\section{Number of participators}

Another difference between events that generate causal antecedent inferences and those that generate causal consequence ones is the number of participators in the activity. Interpersonal verbs are associated with two participators (e.g., John hugged Mary), and gave rise to causal antecedent continuations. This was the case regardless of whether the two participator verbs were actions (hug) or states (love), and whether the Experiencer was the subject (fear) or object (frighten) of the sentence. Transfer verbs include three participators (e.g., John got a ticket from Mary), and gave rise to causal consequence inferences, regardless of whether the Goal of the transfer was the subject (got) or the object (pass). This raises the possibility that number of participators is the crucial difference between eliciting causal antecedent and causal consequence inferences. To test this, we presented Goal-Source verbs with only two participators (e.g., John got a ticket instead of John got a ticket from Mary). When presented with only two participators consequence continuations were still overwhelmingly preferred. This suggests that number of explicitly mentioned participators is not the crucial variable.

\section{Socialness of scenario}

A third difference between the events that triggered causal antecedent inferences and those that triggered causal consequence inferences was the nature of the event itself. Experiment 1 consisted of sentences that depicted an interpersonal scenario, whereas Experiment 2 depicted physical transfer scenarios. To test whether socialness of scenario was critical, in Experiment 5 we transformed the simple transfer scenarios, such as John got a ticket from Mary, into interpersonal ones, such as John got a hug from Mary. We found that people tended to produce causal consequence continuations rather than causal antecedent ones, as would be expected if inferences were being triggered by the scenario-type. One interpretation of this finding is that inferences are being generated based on the literal meaning of the verbs: The meaning of hug triggers causal antecedent inferences but the meaning of got triggers causal consequence inferences. This does not fit very well with the data as the interpretation of the sentences of Experiment 5 does not depend on the literal meaning of got - there is no actual transfer taking place. Rather than the meaning of the verb, other properties of the verbs may be responsible for the different patterns of attribution. One candidate is whether the verb has associated with it a derived adjective.

\section{Derived adjectives and causal antecedent inferences}

In their seminal paper on the implicit causality bias, Brown and Fish (1983) noted that people tend to attribute cause to that participator that has a derived adjective associated with it. For example, in Ted helps Paul the adjective helpful can be derived from help, and would be a trait attributable to Ted; thus when people make a causal attribution to Ted helps Paul, it is to Ted. Brown and Fish, and later Hoffman and Tchir (1990), found that people were more likely to attribute causation to the participator that had a derived adjective associated with it. This suggests a different explanation for the findings that interpersonal verbs elicit inferences about the causal antecedent and transfer verbs elicit inferences about the causal consequent. Perhaps the interpersonal verbs have more derived adjectives associated with the participators than the transfer verbs do. If interpersonal verbs are more likely to have a derived adjective associated with them, then they may be more strongly trait implying, and thus more likely to be associated with the causal antecedent.

In order to test this possibility, we conducted a corpus search for derived adjectives associated with the 128 different verbs used in Experiments 1-5. We counted all derived adjectives that could plausibly be used to refer to one of the participators in the event using the CELEX Lexical Database (Baayen, Piepenbrock, \& Gulikers 1995). There were significantly more adjectives associated with interpersonal verbs $(M=1.1)$ than transfer verbs $(M=0.6), t(127)=2.47$, $p<.02, d=.63$. This is consistent with the proposal that the morphology of the verbs (i.e., whether there is a derived adjective) makes trait implying information more available for interpersonal verbs than for transfer verbs, thus making inferences to causal antecedents for the former set of verbs more likely. But there are some problems with this view.

It has been argued that activation of traits do not require a prior causal inference to have been made, but rather that trait inferences are a simple summary of behavioral or personality information (Hamilton, 1998). To take an example from Hamilton, if someone at a party is socializing with lots of people and I conclude that the person is friendly, I am not attempting to explain why that person is talking to people, but am merely summarizing a pattern of behavior. However, once activated, trait information can be used as the basis for further causal inferencing. Note that the causal inference drawn from a trait term could be to the antecedent or the consequent: John could be charming because he charmed Mary, or as a consequence of this charming Mary. 
Furthermore, as Brown and Fish (1983) noted, English has a productive morphological process which allows a range of suffixes (e.g., -er, -ing, -ablel-ible) to be applied to verbs to form adjectives. The fact that some derived adjectives are more likely to occur could be due to some other variable. For instance, the larger number of derived adjectives associated with the interpersonal verbs could be precisely because these are more likely to receive causal antecedent inferences. Other evidence suggest that trait inferences and causal inferences are mediated by different processes (Greene \& McKoon, 1995; Hilton, Smith, \& Kim, 1995; Semin \& Marsman, 1994). Overall, the link between the existence of derived adjectives and likelihood of a causal antecedent inference being generated remains speculative.

\section{Verb constructions}

Since the literal meaning of the verb is not the central variable in determining whether causal antecedent or causal consequence inferences are generated, a structural variable is implicated. We suggest that the abstract meaning associated with the construction is responsible for the difference in inference type. Goldberg $(1995,2003)$ showed that particular constructions like $X$ verb $Y$ tolfrom $Z$ have a semantics associated with them, just like specific verbs do. This construction has a transfer meaning associated with it, regardless of the verb used to instantiate it.

Evidence for this comes from studies in which novel verbs are used in different constructions (e.g., Fisher, 1994; Kaschak \& Glenberg, 2000). For example, Kaschak and Glenberg (2000) presented participants with sentences that had innovative denominal verbs (i.e., verbs that are created from nouns). For instance, the verb to crutch can be created from the noun crutch, as in Lyn crutched Tom her apple so he wouldn't starve or Lyn crutched her apple so Tom wouldn't starve. Kaschak and Glenberg found that participants were more likely to interpret Lyn crutched Tom her apple to mean Lyn transferred the apple to Tom using her crutch than they were to Lyn crutched her apple, even though both of them use the same innovative verb. This is evidence that the construction provides the transfer meaning. The transfer meaning also remains regardless of whether the verb is used literally to refer to a physical transfer event (as in Experiment 2) or metaphorically to refer to an interpersonal event (as in Experiment 5). It also does not matter if one of the participators is omitted (as in Experiment 4). We suggest that this underlying notion of transfer focuses attention on what happens next, and thus participants produce more causal consequence continuations.

\section{Methodological considerations}

A final methodological point that follows from these studies is that researchers must consider how they are formulating social scenarios when examining causal inferences. Not just scenario-type, but also how the scenario-type is conveyed affects exactly what sorts of inferences are most likely to be considered. The prevalence of inferences to the causal antecedent in much of the literature may reflect choice of linguistic materials, rather than a general preference of the cognitive system. However it should be noted that sampling of interpersonal verbs rather than other sorts of verbs could be due to the prevalence of such verbs in the language - perhaps there are more of these sorts of verbs because causal antecedents tend to be more salient.

\section{Conclusion}

To summarize, the cognitive system does not appear to favor inferences to the causal antecedent or causal consequence blindly. Instead inferences are systematically related to the specific input. We show that a particularly strong cue to which inferences are generated is the particular verb used: If a speaker wants her addressee to entertain causal antecedents she should used a simple sentence such as John hugged Mary; but if she wants to focus her addresses attention to what happened next she should instead use a different formulation, such as John gave Mary a hug. Thus, it is not social scenarios per se that determine the kinds of inferences we make, but the scenario in combination with the particular linguistic formulation that is crucial.

\section{Appendix A. Experimental materials for Experiment 1}

1. Simon answered Anna.

2. Beryl applauded John.

3. Mick calmed down Carol.

4. Trevor censured Caroline.

5. Thomas criticised Debbie.

6. Fraser healed Jean.

7. Arnold helped Jennifer.

8. Liz judged Stephen.

9. Jonathan obeyed Nicola.

10. Rita placated Paul.

11. Paul praised Rita.

12. Ruth reassured Terrence.

13. Bob reprimanded Sally.

14. Amy accepted Ian.

15. Ian accused Amy.

16. Anna agreed with Simon.

17. John approached Beryl.

18. Beth bantered with Rob.

19. Carol betrayed Mick.

20. Caroline chased Trevor.

21. Michael cheated Catherine.

22. Catherine cheered Michael.

23. Derek cheered up Charlotte.

24. Charlotte commanded Derek.

25. Gordon competed with Claire.

26. Claire confided in Gordon.

27. Diana defied Craig.

28. Craig denounced Diana.

29. Keith derided Donna.

30. Elizabeth discouraged Tony. 
31. Alan encouraged Emma.

32. Matthew flattered Gail.

33. Gemma greeted Adam.

34. Jane harassed Ted.

35. Ted harmed Jane.

36. Jennifer hit Arnold.

37. Barry hugged Joan.

38. Joan hurt Barry.

39. Kate insulted Donald.

40. Donald interrupted Kate.

41. Stephen joked with Liz.

42. Lorna kicked Henry.

43. Henry killed Lorna.

44. Meg manipulated Bruce.

45. Nancy murdered Roy.

46. Pamela ordered around Philip.

47. Rose protected Peter.

48. Peter pushed Rose.

49. Samantha restricted Noel.

50. Sandra rushed to Grant.

51. Sue slandered Luke.

52. Luke snubbed Sue.

53. Jack stared at Susan.

54. Susan stopped by Jack.

55. Suzanne supported Richard.

56. Theresa tied up David.

57. Veronica warned Callum.

58. Barbara appalled James.

59. James appeased Barbara.

60. Rob attracted Beth.

61. Debbie daunted Thomas.

62. Jake distracted Ellen.

63. Emma embarrassed Alan.

64. Sebastian fascinated Florence.

65. Gail frightened Matthew.

66. Patrick impressed Joyce.

67. Douglas intrigued Kathy.

68. Kathy irritated Douglas.

69. Nicola obsessed Jonathan.

70. Philip offended Pamela.

71. Ray overexcited Rachel.

72. Andrew shamed Sarah.

73. Sarah shocked Andrew.

74. Richard terrified Suzanne.

75. David troubled Theresa.

76. Tracy uplifted Edward.

77. Callum worried Veronica.

78. Graeme admired Ann.

79. Ann adored Graeme.

80. Donna desired Keith.

81. Eileen despised Kevin.

82. Kevin detested Eileen.

83. Tony disliked Elizabeth.

84. Ellen distrusted Jake.

85. Emily doted on Daniel.

86. Daniel dreaded Emily.

87. Florence feared Sebastian.
88. Adam gaped at Gemma.

89. Jean hated Fraser.

90. Joyce identified Patrick.

91. Mary liked Charles.

92. Charles loathed Mary.

93. Bruce loved Meg.

94. Roy noticed Nancy.

95. Rachel pitied Ray.

96. Terrence recognised Ruth.

97. Sally resented Bob.

98. Noel respected Samantha.

99. Grant saw Sandra.

100. Edward trusted Tracy.

Notes: Items 1-57 are Agent-Patient verbs, items 58-80 Stimulus-Experiencer verbs, and items 81-100 are Experiencer-Stimulus verbs.

\section{Appendix B. Experimental materials for Experiments 2 and 4}

1. Eduardo caught a cold [from Marguerite].

2. Scott caught a ride [from Annette].

3. Gabrielle got a ticket [from Rafael].

4. Carlos got three emails [from Gladys].

5. Claire received a telegram [from Juan].

6. Pablo heard the news [from Jennifer].

7. Allen learned the steps [from Sonia].

8. Art borrowed the notes [from Elizabeth].

9. Bruce accepted an invitation [from Courtney].

10. Pam took some lessons [from Craig].

11. Ed grabbed the megaphone [from Blair].

12. Linda snatched the candy [from Greg].

13. Victor rented a bicycle [from Mimi].

14. Christine inherited big feet [from Nick].

15. Barb purchased a painting [from Dan].

16. Delia bought a stereo [from Ryan].

17. Ginny threw the ball [to Fred].

18. Stacy handed the report [to Christopher].

19. Cathy tossed the egg [to Brett].

20. Bill sent an invitation [to Erin].

21. Rick told the story [to Marie].

22. Jason passed the ball [to Holly].

23. Matt offered the slot [to Tina].

24. Andy rented the house [to Eloise].

25. Wiley loaned a barbecue [to Phyllis].

26. Mike taught a sonata [to Melora].

27. Sean taught the lambada [to Cynthia].

28. Ali brought flowers [to Sam].

29. Brendan gave the pie [to Lisa].

30. Frank sold the couch [to Anna].

31. Betty showed a Van Gough [to Ray].

32. Emily paid \$200 [to Phil].

Notes: Items 1-16 are Goal-Source verbs, and items 1732 are Source-Goal verbs. Words in square brackets were omitted in Experiment 4. 


\section{Appendix C. Experimental materials for Experiment 5}

1. Marguerite caught a glance from Eduardo.

2. Annette caught a whiff from Scott.

3. Rafael got a hug from Gabrielle.

4. Gladys got respect from Carlos.

5. Juan received praise from Claire.

6. Jennifer heard a rumor from Pablo.

7. Sonia learned a language from Allen.

8. Courtney accepted a compliment from Bruce.

9. Craig took abuse from Pam.

10. Blair grabbed the limelight from Ed.

11. Greg snatched a kiss from Linda.

12. Nick inherited patience from Christine.

13. Dan purchased loyalty from Barb.

14. Ryan bought sex from Delia.

15. Fred threw a glance to Ginny.

16. Christopher handed the floor to Stacy.

17. Brett tossed a kiss to Cathy.

18. Erin sent conflicting signals to Bill.

19. Marie told a secret to Rick.

20. Holly passed the blame to Jason.

21. Tina offered support to Matt.

22. Phyllis lent a hand to Wiley.

23. Melora taught the technique to Mike.

24. Cynthia taught manners to Sean.

25. Sam brought joy to Ali.

26. Lisa gave pleasure to Brendan.

27. Anna sold the idea to Frank.

28. Ray showed kindness to Betty.

29. Phil paid attention to Emily.

Notes: Items 1-14 are Goal-Source verbs, and items 15-29 are Source-Goal verbs.

\section{References}

Allbritton, D. (2004). Strategic production of predictive inferences during comprehension. Discourse Processes, 38, 309-322.

Anderson, C. A. (1991). How people think about causes: Examination of the typical phenomenal organization of attributions for success and failure. Social Cognition, 9, 295-329.

Anderson, I., \& Beattie, G. (1996). How important is Kelley's model of the attribution process when men and women discuss rape in conversation? Semiotica, 110, 1-21.

Arnold, J. E. (2001). The effect of thematic roles on pronoun use and frequency of reference continuation. Discourse Processes, 31, 137-162.

Au, T. K. F. (1986). A verb is worth a thousand words: The causes and consequences of interpersonal events implicit in language. Journal of Memory and Language, 25, 104-122.

Baayen, R.H., Piepenbrock, R., \& Gulikers, L. (1995). The CELEX lexical database (Release 2) [CD-ROM]. Philadelphia, PA: Linguistic Data Consortium; University of Pennsylvania [Distributor].

Brown, R., \& Fish, D. (1983). The psychological causality implicit in language. Cognition, 14, 237-273.

Calvo, M. G., Castillo, M. D., \& Schmalhofer, F. (2006). Strategic influence on the time course of predictive inferences in reading. Memory \& Cognition, 34, 68-77.

Carlston, D. E., \& Skowronski, J. J. (1994). Savings in the relearning of trait information as evidence for spontaneous inference generation. Journal of Personality and Social Psychology, 66, 840-856.
Carlston, D. E., Skowronski, J. J., \& Sparks, C. (1995). Savings in relearning: II. On the formation of behavior-based trait associations and inferences. Journal of Personality and Social Psychology, 69, 420-436.

Chafe, W. (1979). The flow of thought and the flow of language. In T. Givon (Ed.), Discourse and syntax (pp. 159-181). New York: Academic Press.

Clark, H. H. (1973). Language as fixed-effect fallacy: Critique of language statistics in psychological research. Journal of Verbal Learning and Verbal Behavior, 12, 335-359.

Cohen, J. (1960). A coefficient of agreement for nominal scales. Educational and Psychological Measurement, 20, 37-46.

Corrigan, R. (1988). Who dun it: The influence of actor patient animacy and type of verb in the making of causal attributions. Journal of Memory and Language, 27, 447-465.

Corrigan, R. (1992). The relationship between causal attributions and judgments of the typicality of events described by sentences. British Journal of Social Psychology, 31, 351-368.

Einhorn, H. J., \& Hogarth, R. M. (1986). Judging probable cause. Psychological Bulletin, 99, 3-19.

Faul, F., \& Erdfelder, E. (1992). GPOWER: A priori, post-hoc, and compromise power analyses for MS-DOS. Bonn, Germany: Bonn University, Department of Psychology.

Fenker, D. B., Waldmann, M. R., \& Holyoak, K. J. (2005). Accessing causal relations in semantic memory. Memory \& Cognition, 33, 1036 1046.

Fiedler, K., \& Semin, G. R. (1988). On the causal information conveyed by different interpersonal verbs: The role of implicit sentence context. Social Cognition, 6, 21-39.

Fiedler, K., Semin, G. R., \& Koppetsch, C. (1991). Language use and attributional biases in close personal relationships. Personality and Social Psychology Bulletin, 17, 147-155.

Fincher-Kiefer, R. (1993). The role of predictive inferences in situation model construction. Discourse Processes, 16, 99-124.

Fisher, C. (1994). Structure and meaning in the verb lexicon: Input for a syntax-aided verb learning procedure. Language and Cognitive Processes, 9, 473-518.

Fiske, S. T., \& Taylor, S. E (1991). Social cognition (2nd ed.). London: McGraw-Hill.

Försterling, F., \& Groeneveld, A. (1983). Attribution of causes for the election result: Testing of hypotheses of attribution theory in a field-study based on the 1981 Municipal Elections in Niedersachsen. Zeitschrift Fur Sozialpsychologie, 14, 262-269.

Garvey, C., \& Caramazza, A. (1974). Implicit causality in verbs. Linguistic Inquiry, 5, 459-464.

Goldberg, A. E. (1995). A construction grammar approach to argument structure. Chicago: University of Chicago Press.

Goldberg, A. E. (2003). Constructions: A new theoretical approach to language. Trends in Cognitive Sciences, 7, 219-224.

Graesser, A. C., Millis, K. K., \& Zwaan, R. A. (1997). Discourse comprehension. Annual Review of Psychology, 48, 163-189.

Graesser, A. C., Singer, M., \& Trabasso, T. (1994). Constructing inferences during narrative text comprehension. Psychological Review, 101, 371395 .

Greene, S. B., \& McKoon, G. (1995). Telling something we can't know: Experimental approaches to verbs exhibiting imlicit causality. Physchology Science, 6, 262-270.

Hamilton, D. L. (1988). Casual attribution viewed from an informationprocessing perspective. In D. Bar-Tal \& A. W. Kruglanski (Eds.), The Social Psychology of Knowledge (pp. 359-385). Cambridge: Cambridge University Press.

Hassin, R. R., Bargh, J. A., \& Uleman, J. S. (2002). Spontaneous causal inferences. Journal of Experimental Social Psychology, 38, 515-522.

Hastie, R. (1984). Causes and effects of causal attribution. Journal of Personality and Social Psychology, 46, 44-56.

Heider, F. (1958). The psychology of interpersonal relations. New York: Wiley.

Hewstone, M. (1989). Causal attribution: From cognitive processes to collective beliefs. Oxford: Blackwell. 
Hilton, D. J., \& Slugoski, B. R. (1986). Knowledge-based causal attribution: The abnormal conditions focus model. Psychological Review, 93, 75-88.

Hilton, D. L., Smith, R. H., \& Kim, S. H. (1995). Processes of causal explanation and dispositional attribution. Journal of Personality and Social Psychology, 68, 377-387.

Hoffman, C., \& Tchir, M. A. (1990). Interpersonal verbs and dispositional adjectives: The psychology of causality embodied in language. Journal of Personality and Social Psychology, 58, 765-778.

Hopper, P. J. (1979). Aspect and foregrounding in discourse. In T. Givon (Ed.), Discourse and syntax (pp. 213-241). New York: Academic Press.

Kanazawa, S. (1992). Outcome or expectancy: Antecedent of spontaneous causal attribution. Personality and Social Psychology Bulletin, 18, $659-668$.

Kaschak, M. P., \& Glenberg, A. M. (2000). Constructing meaning: The role of affordances and grammatical constructions in sentence comprehension. Journal of Memory and Language, 43, 508-529.

Keefe, D. E., \& McDaniel, M. A. (1993). The time-course and durability of predictive inferences. Journal of Memory and Language, 32, 446-463.

Keenan, J. M., Baillet, S. D., \& Brown, P. (1984). The effects of causal cohesion on comprehension and memory. Journal of Verbal Learning and Verbal Behavior, 23, 115-126.

Kelley, H. H. (1967). Attribution theory in social psychology. Nebraska Symposium on Motivation, 15, 192-238.

Landis, J. R., \& Koch, G. G. (1977). The measure of observer agreement for categorical data. Biometrics, 33, 159-174.

Lau, R. R. (1984). Dynamics of the attribution process. Journal of Personality and Social Psychology, 46, 1017-1028.

Lau, R. R., \& Russell, D. (1980). Attributions in the sports pages. Journal of Personality and Social Psychology, 39, 29-38.

Levin, B. (1993). English verb classes and alternations: A preliminary investigation. Chicago: University of Chicago Press.

Maass, A., \& Arcuri, L. (1992). The role of language in the persistence of stereotypes. In G. R. Semin \& K. Fiedler (Eds.), Language, interaction and social cognition (pp. 129-143). London: Sage.

Mackie, J. L. (1980). The cement of the universe: A study of causation. Oxford: Clarendon.

Magliano, J. P., Baggett, W. B., Johnson, B. K., \& Graesser, A. C. (1993). The time-course of generating causal antecedent and causal consequence inferences. Discourse Processes, 16, 35-53.

McKoon, G., \& Ratcliff, R. (1986). Inferences about predictable events. Journal of Experimental Psychology: Learning, Memory, and Cognition, 12, 82-91.

Murray, J. D., Klin, C. M., \& Myers, J. L. (1993). Forward inferences in narrative text. Journal of Memory and Language, 32, 464 473.

Nelson, K. (1986). Event knowledge: Structure and function in development. Hillsdale, NJ: Erlbaum.

Rudolph, U., \& Försterling, F. (1997). The psychological causality implicit in verbs. Psychological Bulletin, 121, 192-218.

Sacks, H. (1972). On the analyzability of stories by children. In J. J. Gumperz \& D. Hymes (Eds.), Directions in sociolinguistics (pp. 325-345). New York: Holt, Rinehart and Winston.
Schank, R. C. (1986). Explanation patterns: Understanding mechanically and creatively. Hillsdale, NJ: Erlbaum.

Semin, G. R., \& Fiedler, K. (1988). The cognitive functions of linguistic categories in describing persons: Social cognition and language. Journal of Personality and Social Psychology, 54, 558-568.

Semin, G. R., \& Fiedler, K. (1989). Relocating attributional phenomena within a language-cognition interface: The case of actors and observers perspectives. European Journal of Social Psychology, 19, 491-508.

Semin, G. R., \& Fiedler, K. (Eds.). (1992). Language, interaction and social cognition. London: Sage Publications.

Semin, G. R., \& Marsman, J. G. (1994). "Multiple inference-inviting properties" of interpersonal verbs: Event instigation, dispositional inference, and implicit causality. Journal of Personality and Social Psychology, 67, 836-849.

Stevenson, R. J., Crawley, R. A., \& Kleinman, D. (1994). Thematic roles, focus and the representation of events. Language and Cognitive Processes, 9, 519-548.

Trabasso, T., \& Magliano, J. P. (1996). Conscious understanding during comprehension. Discourse Processes, 21, 255-287.

Trabasso, T., \& Sperry, L. L. (1985). Causal relatedness and importance of story events. Journal of Memory and Language, 24, 595-611.

Trabasso, T., \& Vandenbroek, P. (1985). Causal thinking and the representation of narrative events. Journal of Memory and Language, 24, 612 630 .

Turnbull, W. (1986). Everyday explanation: The pragmatics of puzzle resolution. Journal for the Theory of Social Behavior, 16, 141-160.

Uleman, J. S. (1999). Spontaneous versus intentional inferences in impression formation. In S. Chaiken \& Y. Trope (Eds.), Dual-process theories in social psychology (pp. 141-160). New York: Guilford.

Uleman, J. S., Newman, L. S., \& Moskowitz, G. B. (1996). People as flexible interpreters: evidence from spontaneous trait inference. Advances in Experimental Social Psychology, 28, 211-279.

Van den Broek, P. (1990). The causal inference maker: Towards a process model of inference generation in text comprehension. In D. A. Balota, G. B. Flores d' Arcais, \& K. Rayner (Eds.), Comprehension processes in reading (pp. 423-445). London: Erlbaum.

Van der Meer, E., Beyer, R., Heinze, B., \& Badel, I. (2002). Temporal order relations in language comprehension. Journal of Experimental Psychology: Learning, Memory, and Cognition, 28, 770-779.

Weiner, B. (1985). Spontaneous causal thinking. Psychological Bulletin, 97, 74-84.

Winter, L., \& Uleman, J. S. (1984). When are social judgments made: Evidence for the spontaneousness of trait inferences. Journal of Personality and Social Psychology, 47, 237-252.

Wyer, R. S., \& Srull, T. K. (1989). Memory and cognition in its social context. Hillsdale, NJ: Erlbaum.

Zwaan, R. A. (1996). Processing narrative time shifts. Journal of Experimental Psychology: Learning, Memory, and Cognition, 22, 11961207.

Zwaan, R. A., \& Radvansky, G. A. (1998). Situation models in language comprehension and memory. Psychological Bulletin, 123, 162-185. 